\title{
Negative quantities in mechanics: a fine-grained math and physics conceptual blend?
}

\author{
Suzanne White Brahmia \\ Department of Physics, University of Washington, Box 351560, Seattle, WA 98195-1560
}

\begin{abstract}
Physics experts move fluidly between varied meanings of the negative sign associated with physical quantities. Although researching student understanding of negative numbers is common in mathematics education, little research has been published that focusses on students' interpretation of negativity in the context of physics quantities. In this study, we investigated student reasoning about the negative sign associated with acceleration, work and position. A theoretical model of the mathematical nature of negativity guided our development of three open-ended survey items which were administered to students in introductory calculus-based physics courses. We observed that students who use vector direction as a resource to reason about negative acceleration and negative work tend to be more flexible across the three natures of negativity probed in our survey than students who use predominantly motion and energy-based reasoning. We followed up with a secondary study in which the intervention group was asked to explain their reasoning from a mathematical perspective in the context of negative work, and observed that this epistemic nudge led to significant improvement. We interpret the productive reasoning space associated with physics quantity as a tight cognitive blend in which the physics and the mathematics are indistinguishable. This interpretation departs from prior models based on separable physics worlds and math worlds.
\end{abstract}

\section{INTRODUCTION}

Unlike physics experts, who never attribute a "negative direction" to negative potential energy - but would readily do so when considering a negative component of velocity, novices struggle to understand the many roles a negative sign can play in physics contexts. Developing flexibility with negative numbers is a known challenge in math education. Vlassis, who has research negative numbers extensively, used written diagnostic questions and interviews with Belgian algebra students to investigate the understanding of negative numbers [1]. They found that full understanding of the concept of a negative number required that students develop flexibility with the various ways negative numbers are used in context, i.e., with the "negativity" of the number. Based on their research, Vlassis modified prior models to produce a "map" that describes these different uses (reproduced in Table I.)

Negativity in the context of physics quantities involve these three natures and perhaps more. Quantity also carries physical meaning that is part of, and often idiosyncratic to, the quantity itself (e.g. negative work, negative entropy change). While mathematics educators actively research student understanding of negative numbers, there is surprisingly little work that has been published in the context of physics to explore student understanding of the meaning of negative physical quantities $[2,3]$.

Sherin observed patterns in student reasoning by studying successful problem solving behaviors of $3^{\text {rd }}$ semester engineering students taking physics at a highly selective university [4]. Regarding negativity, Sherin uses the symbolic form "competing terms cluster" to describe the quantification of opposites in physics. This form includes the notion of zero to represent balance, and positive and negative quantities as competing terms in an expression. He observes that flexibility with the competing terms cluster is a feature of expert problem solving. We interpret use of this symbolic form as demonstrating flexibility with symmetrical nature of the minus sign as described by Vlassis (see Table I) [1].

Bajracharya and colleagues investigated student understanding of integration in the context of $P-V$ diagrams in introductory physics [5]. Their results suggest difficulties with the criteria that determine the sign of a definite integral. Students struggle with the concept of a negative area, and with positive and negative directions of single-variable integration. We interpret this struggle to be rooted in an incomplete understanding of the symmetrical nature of the minus sign in the calculus context.

In a prior study, Brahmia and Boudreaux found that calculus-based physics students struggled to make sense of negative physics quantities [6]. Students struggled less with the unary, or "isolated number", nature of negativity (onedimensional position), and struggled more with negative scalar quantities, commonly associating the sign of the scalar with the direction of one of the factor vectors. The authors concluded that physics contexts may overwhelm some students' conceptual flexibility with negative numbers.

Sealy and Thompson report on a context in which physics helps math students make sense of negativity in calculus [7]. They interviewed math majors as part of a study to uncover how they made sense of a negative definite integral. The researchers observed that invoking a physics example of a stretched spring helped catalyze sense making - the physics helped them to make sense of an abstract binary nature of the negative sign. 
Table I: Negativity: A map of the different uses of the negative sign in elementary algebra; the triple nature of the minus sign [1].

\begin{tabular}{|c|c|c|}
\hline Unary & Symmetrical & Binary \\
\hline $\begin{array}{l}\text { Structural } \\
\text { signifier }\end{array}$ & $\begin{array}{l}\text { Operational } \\
\text { signifier }\end{array}$ & $\begin{array}{l}\text { Operational } \\
\text { signifier }\end{array}$ \\
\hline $\begin{array}{l}\text { Subtrahend } \\
\text { Relative number } \\
\text { Isolated number } \\
\text { Formal concept } \\
\text { of negative } \\
\text { number }\end{array}$ & $\begin{array}{l}\text { Taking } \\
\text { opposite of, } \\
\text { or inverting, } \\
\text { the operation }\end{array}$ & $\begin{array}{l}\text { Completing } \\
\text { Taking away } \\
\text { Difference between } \\
\text { two numbers } \\
\text { Movements on the } \\
\text { number line }\end{array}$ \\
\hline
\end{tabular}

The current study extends our prior research on negative physics quantities in an effort to better understand whether calling on mathematics resources for reasoning about physics quantities is productive in developing flexibility with the three natures of negativity in mechanics [6] - can math do for physics students what physics did for math students in the Sealy and Thompson study [7]? We approach this work from a resources perspective, looking closely at student use of one-dimensional vector thinking for understanding negativity in the contexts of acceleration, work and position. This study focusses on answering the following research question: Does explicit reasoning about mathematical objects (the direction of a vector and the scalar product of two vectors) catalyze productive reasoning about negative work and one-dimensional acceleration?

Table II: Mechanics negativity survey items

\begin{tabular}{|c|c|c|}
\hline $\begin{array}{l}\text { Unary } \\
\text { structural } \\
\text { signifier }\end{array}$ & $\begin{array}{l}\text { Symmetrical } \\
\text { operational } \\
\text { signifier }\end{array}$ & $\begin{array}{l}\text { Binary } \\
\text { operational } \\
\text { signifier }\end{array}$ \\
\hline $\begin{array}{l}\text { Direction of a } \\
\text { vector } \\
\text { component }\end{array}$ & $\begin{array}{l}\text { Signifies work } \\
\text { results in decreasing } \\
\text { the system energy, } \\
\text { not increasing it }\end{array}$ & $\begin{array}{l}\text { Position } \\
\text { relative to an } \\
\text { origin }\end{array}$ \\
\hline $\begin{array}{l}\text { 1: An object } \\
\text { moves along } \\
\text { the x-axis, and } \\
\text { the } \\
\text { acceleration is } \\
\text { measured to be } \\
\mathrm{a}_{\mathrm{x}}=-8 \mathrm{~m} / \mathrm{s}^{2} \text {. } \\
\text { Describe in } \\
\text { your own } \\
\text { words the } \\
\text { meaning of the } \\
\text { negative sign } \\
\text { in the } \\
\text { mathematical } \\
\text { statement } \\
\text { " } \mathrm{a}_{\mathrm{x}}=-8 \mathrm{~m} / \mathrm{s}^{2} \text { ". }\end{array}$ & $\begin{array}{l}\text { 2: A hand exerts a } \\
\text { horizontal force on a } \\
\text { block as the block } \\
\text { moves on a } \\
\text { frictionless } \\
\text { horizontal } \\
\text { surface. For a } \\
\text { particular interval } \\
\text { of the motion, the } \\
\text { work W done by the } \\
\text { hand is W = - } 2.7 \\
\text { J. Describe in your } \\
\text { own words the } \\
\text { meaning of the } \\
\text { negative sign in the } \\
\text { mathematical } \\
\text { statement } \\
\text { "W=-2.7 J". }\end{array}$ & $\begin{array}{l}\text { 3: A cart is } \\
\text { moving along } \\
\text { the } x \text {-axis. At a } \\
\text { specific instant, } \\
\text { the cart is at } \\
\text { position } x=-7 \\
\text { m. Describe in } \\
\text { your own } \\
\text { words the } \\
\text { meaning of the } \\
\text { negative sign in } \\
\text { the } \\
\text { mathematical } \\
\text { statement } \\
\text { " } x=-7 \mathrm{~m} \text { ". }\end{array}$ \\
\hline
\end{tabular}

\section{METHODOLOGY AND FINDINGS}

We approach the survey development using Vlassis' framework for the natures of negativity; we developed one survey question for each of the three natures in the context of mechanics' quantities. The first survey item probes student understanding of the unary nature of the negative sign, the second probes the symmetrical nature, and the third, the binary nature (see Table I). On the first item students must interpret the sign of a vector component (acceleration). On the second item, which assesses the ability to quantify opposite actions, students must interpret the sign of the work done by an agent. Finally, on the third item, designed to probe the ability to coordinate a measured quantity with its reference, students must interpret the sign of position vector component. Table II presents all three items.

We refined the survey questions by first establishing face validity with two physics faculty members and two math faculty members. We then conducted student interviews with four students, and refined the item wording for clarity. We describe elsewhere the subsequent development of multiple choice versions [6]. The open-ended survey items used in the studies described below appear in Table II.

\section{Experiment \#1: Methodology}

The survey was administered supervised and in-class to 84 introductory calculus-based mechanics students at the end of the semester in a large, selective state university. The items were not graded for correctness, though students were awarded points for completing the survey.

We coded student responses based on the dominant reasoning patterns observed in the acceleration and work survey items. We omitted the position question in our coding since most students in calculus-based physics answer this question correctly; position along a number line is the main context for negative numbers in middle school math classes. We saw that student reasoning fell into three categories: 1) arguments based on the motion of the object and/or energy of the system, 2) arguments based on the directions of vector quantities, 3) both motion/energy and vector directions.

The surveys were coded by two independent coders, and the interrater reliability was above $90 \%$. Examples of student reasoning in each category for the acceleration and work survey items are shown in Table III.

\section{Experiment \#1: Findings}

We use the number of survey questions answered correctly as a measure of negativity flexibility, where we've called the 0 or 1 correct group "inflexible/inconsistently flexible." Table IV shows the percentage of students in our sample who answered 0 , only 1 item, only 2 items, or all 3 negativity survey items correctly. Nearly half of the students demonstrated "inflexible" on these items. 


\begin{tabular}{|c|c|c|c|}
\hline \multicolumn{2}{|c|}{ Reasoning: } & \multirow[b]{2}{*}{\begin{tabular}{ll}
\multicolumn{3}{l}{ motion/energy } \\
"If my velocity is \\
positive I am \\
decreasing my \\
speed. If my \\
velocity & is \\
negative I am \\
increasing \\
speed." my
\end{tabular}} & \multirow[b]{2}{*}{$\begin{array}{l}\text { vector direction } \\
\text { "The negative sign } \\
\text { means the direction } \\
\text { of the acceleration. If } \\
\text { you label the right } \\
\text { side of the } x \text {-axis "+", } \\
\text { the } a_{x} \text { is to the left } \\
\text { and vice versa." }\end{array}$} \\
\hline$\Xi$ & 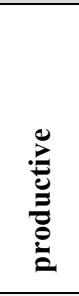 & & \\
\hline 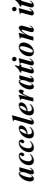 & 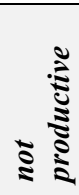 & $\begin{array}{l}\text { "The object is } \\
\text { slowing down at a } \\
\text { rate of } 8 \mathrm{~m} / \mathrm{s}^{2} \text { " }\end{array}$ & $\begin{array}{l}\text { "velocity has a } \\
\text { direction and the } \\
\text { acceleration is } \\
\text { opposing it in this } \\
\text { instance." }\end{array}$ \\
\hline & 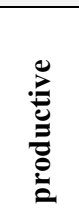 & $\begin{array}{l}\text { "Negative work } \\
\text { here means that } \\
\text { the hand is taking } \\
\text { energy away from } \\
\text { the block/surface } \\
\text { system." }\end{array}$ & $\begin{array}{l}\text { "The object moves in } \\
\text { the direction opposite } \\
\text { to the applied force." }\end{array}$ \\
\hline 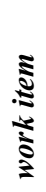 & 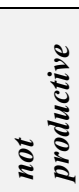 & $\begin{array}{l}\text { "Work was done } \\
\text { using a negative } \\
\text { force." }\end{array}$ & $\begin{array}{l}\text { "The block exerts a } \\
\text { force in one direction } \\
\text { while the hand exerts } \\
\text { a force in the } \\
\text { opposite direction." }\end{array}$ \\
\hline
\end{tabular}

Table III: Examples of productive and unproductive student reasoning for the motion/energy code and for the vector direction code.

Figure 1 shows the distribution of the predominant kind of reasoning that students used, clustered in to two groups; those who answered 1 or 0 (inflexibility) and those who answered 2 or 3 (emerging flexibility.) We observed more coherence across responses to the survey items when students used vector direction reasoning; those students were more likely to demonstrate flexibility with negativity in mechanics as evidenced by getting more than one of the items correct. There was a higher likelihood of fragmented reasoning when students relied solely on a verbal description of motion or energy.

Fragmented reasoning was particularly evident on the work survey item. Based on these observed patterns, we developed the following hypothesis: Calling on resources associated with vector directions, and how vectors combine, can improve students' flexibility with negativity in mechanics. We designed and conducted a follow-up experiment to test this hypothesis, described in the next section.

Table IV: Percentage of students who answer 0 , only 1 , only 2 , and all 3 negativity survey items correctly

\begin{tabular}{|c|c|c|c|}
\hline 0 of 3 & 1 of 3 only & 2 of 3 only & All 3 \\
\hline $17 \%$ & $30 \%$ & $45 \%$ & $8 \%$ \\
\hline
\end{tabular}

Figure 1: Distribution of reasoning codes for students demonstrating a) little or no flexibility, and b) emerging or strong flexibility with the three natures of negativity.

\section{b) Emerging Flexibile/Flexible: 2 or 3 correct $(n=45)$}

$$
\begin{aligned}
& \text { Vector } \\
& \text { Directions } \\
& \text { Both }
\end{aligned}
$$$$
\text { Motion/Energy }
$$

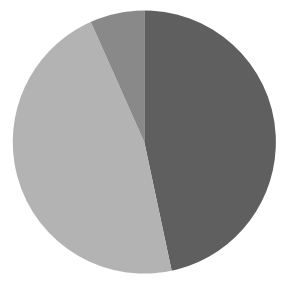
a) Inflexible/Inconsistently flexible:
O or 1 Correct $(n=39)$

Motion/Energy
Vector
Directions
Both

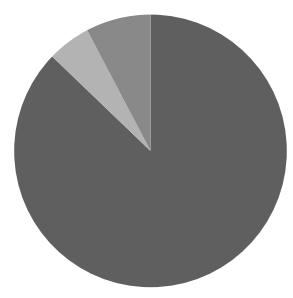

\section{Experiment \#2: Methodology}

For this experiment, we used the work survey item only. Since we didn't know if there would be any measurable difference, we wanted to increase the sample size in order to make an unambiguous measurement - using only one item kept the coding tractable with a large sample size. We opted to use the work question because as a scalar product of two vector quantities it involves the richest vector-direction reasoning, and students struggle with its physical interpretation. In a prior study, we reported $<50 \%$ correctness rates on a multiple-choice version of this survey item with a statistically identical population [6]. We designed experiment 2 to explore the following question: Does priming students to reason from a mathematical perspective about work have an impact on their reasoning about the meaning of negative work?

We created two versions that were assigned at random to a sample of $n=441$ students after instruction but before the end of the term in a calculus-based mechanics course at a selective state university. The surveys were administered online, and were graded for completion but not for correctness. Version 1 is shown in Table II, and Version 2 differed only with the addition of the four bold words:

"From a mathematical perspective, describe the meaning of the negative sign in the quantity "- $2.7 \mathrm{~J}$ ". 


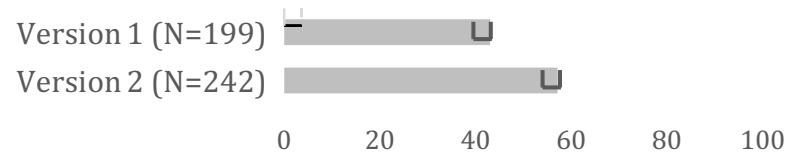

Figure 2: Percentage correct on the two versions of the work survey item. $\mathrm{N}($ version 1$)=199,43 \%$; std err $=3.5 \%$; $\mathrm{N}($ version 2$)=242,57 \%$; std err $=3.0 \%$.

\section{Experiment \#2: Findings}

The student responses were coded using a binary scheme - correct or incorrect - regardless of whether students used purely motion/energy reasoning, purely vector direction reasoning or a combination of both. The surveys were coded by two independent coders, and the interrater reliability was above $90 \%$. The results are shown in Fig. 2 along with the binary standard error.

\section{DISCUSSION}

Three features stand out from the data: 1) roughly half of calculus-based mechanics students in our sample demonstrate basic flexibility with the negativity of physics quantities, 2) flexibility with the negativity may be catalyzed by calling on mathematical resources related to vector orientation and operations - even when the negative sign doesn't imply direction, and 3) reasoning about negative work may be less fragmented when students' use mathematical objects to inform their reasoning.

We interpret these features as evidence that negativity in physics poses a significant a cognitive challenge; those who subconsciously reason using mathematical resources appear to be more flexible in physics contexts, and students can be primed to call on those resources. Seen through the lens of conceptual blending, we suggest that the math-physics blending may be tighter than has been previously discussed in theoretical models proposed in PER $[8,9]$. Rather than a back and forth between the math world and the physics world, we find it productive to think in terms of symbiotic cognition in which a homogeneous blended cognitive space, at a subconscious level, can be cultivated and can catalyze

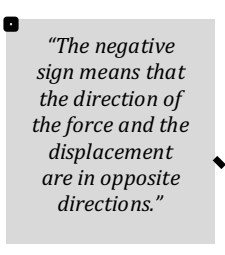

Math World
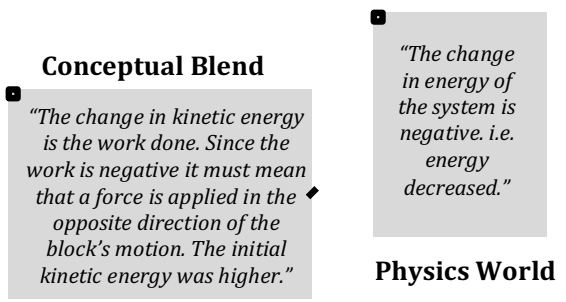

Physics World
Figure 3: The center quote from our sample characterizes the blended space, surrounded by quotes that characterize the math world (LHS) and the physics world (RHS)

cognitive flexibility; the physics informs the mathematical thinking which informs physics reasoning (see Fig. 3).

\section{CONCLUSION}

This study reveals student difficulties and reasoning patterns about physics at a small grain size - negativity of physics quantity. We have observed that calling on mathematical resources can catalyze and strengthen physics reasoning in the context of negativity. Due to the static nature of the data corpus, the study is limited in that it does not reveal typical students' in the moment thinking. The discussion at this stage is thereby preliminary - we don't know how many students rejected calling on mathematics resources because the study was conducted in a physics course. Regardless, an implication for instruction is that physics learning environments designed to develop students' proclivity to call on their mathematical resources will likely enrich the learning outcomes. Our future work will include structured interviews to better understand students' in the moment thinking by observing their reasoning trajectories. We conclude that, for students engaged in learning the two disciplines, mathematics and physics can breathe life into each other. Our job is to figure out how.

\section{ACKNOWLEDGEMENTS}

I would like to acknowledge Andrew Boudreaux for collaboration and support developing the assessment items. I would also like to thank Chaz Ruggieri and Andrew Boudreaux for their assistance with data analysis.
[1] J. Vlassis, Learn Instr 14, 5 (2004).

[2] J. Bishop et al.,J. Res. Math. Educ., 45, 1,(2014). pp19-61

[3] I. Peled,\& D.W. Carraher, in Algebra in the early grades, Edited by J. Kaput, et al., (Erlbaum, Mahwah, NJ, 2007). pp. 303-327

[4] B. Sherin, Cognition Instruct 19, 4 (2001).

[5] R. R. Bajracharya, et al., in 2011 Phys. Educ. Res. Conf., edited by C. Singh, et al. (Omaha, 2012).p.111
[6] S. Brahmia and A. Boudreaux, in Proc. of the 19th Annu. Conf. on RUME, Edited by T. FukawaConnelly, et al., (Pittsburgh, 2016) p. 76

[7] V. Sealy and J. Thompson, , in Proc. of the 19th Annu. Conf. on RUME, Edited by T. FukawaConnelly, et al.,(Pittsburgh, 2016) p. 410

[8] G. Fauconnier and M.Turner, The Way We Think: Conceptual Blending And The Mind's Hidden Complexities, (Basic Books, New York, 2008).

[9] O. Uhden, et al., Sci. \& Educ. 21, (2012). 